\title{
CHANGING LIVES FROM BEPZ TO FAB: THE IMPACT OF EPZ TO THE SOCIO-ECONOMIC AND CULTURAL LIFE OF THE INHABITANTS OF MARIVELES BATAAN
}

\author{
Rosaly P. Malate
}

\begin{abstract}
The Bataan Export Processing Zone (BEPZ) plays an important role in the industrialization of the country as cited in many existing studies. This article, moreover, is an assessment of the impact of the Export Processing Zone not on the national economy but particularly on the local community of Mariveles in the province of Bataan in the Philippines. The article is a historical description with a view of sharing the synoptic picture of changes related to the socio-cultural and economic life of the inhabitants of the town of Mariveles Bataan as brought about by the development of the export-processing zone and the Freeport area. The methodology used in this research is qualitative approach supplemented by a descriptive statistics derived from primary and secondary sources of information. Finally, the article disputes the argument of some critics that there is no gain in the establishment of the EPZ because the government and foreign loans heavily fund it. The Bataan Export Processing Zone is successful with reference to the attainment of its main objective of increasing domestic employment. The socio-economic benefits resulted from the establishment of the economic zone and the provisions of the infrastructure external to the zone proper have positive spillover on the local community and eventually on the national economy.

\section{Introduction}

The history of Mariveles ${ }^{1}$ Bataan $^{2}$ was not too different from that of other towns or islands of the Philippines. Formerly known as the village of Camaya which means "resting place," Mariveles served as the "stop-over" for merchants and Chinese traders. It became the resting place and refilling station for merchant ships before coming into Manila Bay. In 1754, Governor General Pedro Manuel Arandia established the province of Bataan out of the territories belonging to Pampanga and the Corregimiento ${ }^{3}$ de Mariveles. ${ }^{4}$ When the revolution escalated, Mariveles also figured in the uprising against Spain with a handful of Katipuneros ${ }^{5}$ laying siege on a Spanish camp. On the turn of the $19^{\text {th }}$ century, the Philippines fell under the American rule. When the American soldiers reached Mariveles, they established the country's first quarantine station in the Old Spanish Leprosarium Hospital. The purpose of quarantine was to check all incoming and outgoing shipments from any communicable and deadly diseases from spreading. That quarantine station was now the National Mental Ward, a hospital for mental patient. Mariveles served as the temporary camp for captured Filipino and American soldiers who defended Corregidor and Bataan during the Second World War. Thus, the gruelling "Death March" to Capaz, Tarlac started in Mariveles. ${ }^{6}$ In the exact site of the start of the Death March was a commemorative Marker to remember the Filipino-American heroism.
\end{abstract}


Figure 1. Death March Starting Point ${ }^{7}$

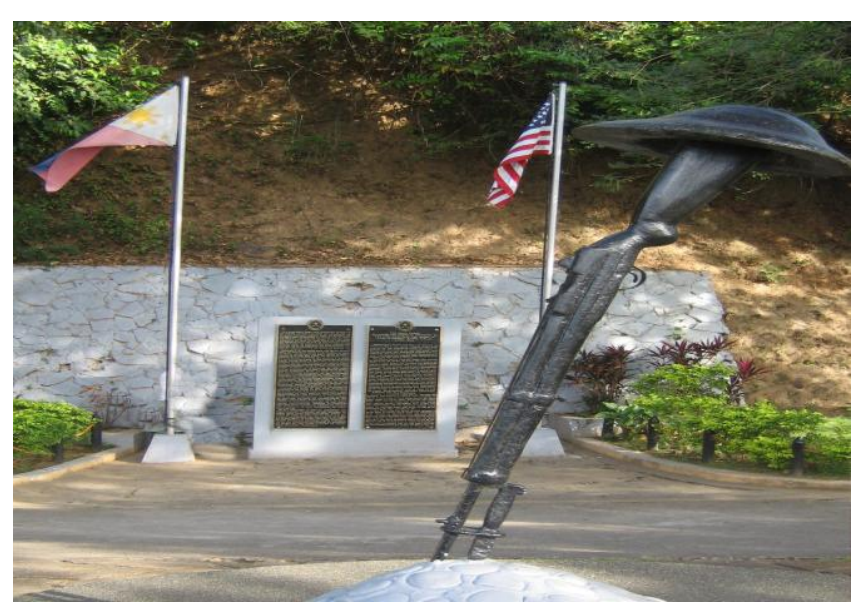

Figure 2. Commemorative Site where Gen. Edward P. King Surrendered to Japanese Army ${ }^{8}$

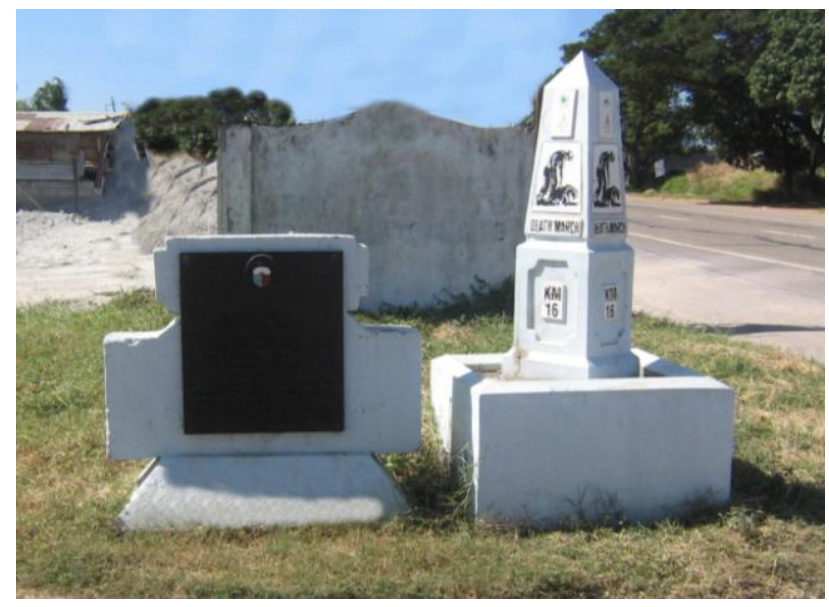

Similar with other Philippine provinces devastated by war, Mariveles faced the problem of reconstruction, rehabilitation of economy and the upliftment of the socio-cultural life of the people. Since then Mariveles remained a rural area wherein people were highly dependent on agriculture, forestry, and fishing for survival. It was only when the Bataan Export Processing Zone (BEPZ) ${ }^{9}$ was established and begun its operation in 1972 that certain socio-economic and cultural changes occurred among the inhabitants of Mariveles Bataan. The municipality of Mariveles became a port of entry. The Bataan Export Processing Zone (BEPZ) was a result of Philippine government's decision to focus its development efforts in the field of foreign-owned, export-oriented industrialization. ${ }^{10}$ On November 20, 1972, Presidential Decree No. 66 revised Republic Act No. 5490 and created the Export Processing Zone Authority (EPZA). The EPZA became responsible for the operation, administration, and management of the Bataan Export Processing Zone. The establishment of the BEPZ hoped to give realization to then President Ferdinand Marcos' dream of industrialization through export promotion. ${ }^{11}$ Its' establishment expected to attract transnational enterprises to invest in export manufacturing. Considered as a policy objective, the creation of export-processing zone aimed at enhancing the country's productive capacity in manufactured goods, especially for the world market. ${ }^{12}$ The succeeding Philippine Presidents after Marcos continued to promote foreign investments in the export processing zones by signing in more laws. In 1994, President Ramos' Government manifested its intention to promote export as a focal strategy for a sustainable agri-industrial development through the passage of the Export Development Act of 1994. Afterwards, on May 17, 1995 President Ramos signed into law Republic Act No. 7916 to encourage more foreign investments in the export-processing zones. The Republic Act No. 7916 otherwise known as the Special Economic Zone Act of 1995 created the Philippine Economic Zone Authority (PEZA) that replaced the former Bataan Export Processing Zone (BEPZ). Similarly, Bataan Economic Zone $(B E Z)^{13}$ replaced Export Processing Zone Authority (EPZA). Through PEZA, the government hoped to promote and speed up a viable and balanced industrial, economic, and social development that would uplift the living conditions of the people especially in the countryside. Republic Act No. 7916 offers expanded incentives to foreign investors and creates more types of 
economic zones to add to the number of areas where investors could invest. ${ }^{14}$ In later years, PEZA-BEZ had conflict with the local government of Mariveles. Critics said that conflict happened because of political rivalry between BEZ Administrators and the local and provincial government of Bataan. Others claimed that Mariveles and the whole province of Bataan did not benefit much from the presence of local and foreign investors because the income of BEZ went to PEZA and to the national government. Only a small portion of the income went to the local treasury. Furthermore, the economic activity and growth in the surrounding province of Bataan due to the development of the Subic Bay Freeport Zone (SBFZ) in 1992 and Clark Special Economic Zone (CSEZ) in 1995, respectively, cause a setback in the operation of BEZ. SFFZ and CSEZ became BEZ's competitor in attracting foreign investments because of their better facilities and geographical location. The development in the BEZ stagnated and then decline rapidly because of decreasing number of firms. The number of firms determined the success of the zone, the employment generation, and foreign direct investments. To augment the continuing decline of the Bataan Economic Zone President Gloria Arroyo enacted Republic Act No. 9728 in October 23, 2009. Republic Act No. 9728 or the Freeport Area of Bataan Act converted the Bataan Economic Zone into a Freeport Area. The Freeport Area of Bataan (FAB) was a special economic zone and Freeport with a dedicated governing authority, the Authority of the Freeport Area of Bataan (AFAB). The Act allowed the zone to fulfill its original mandate of becoming a catalyst for progress and development and to create employment and livelihood opportunities to the people. ${ }^{15}$ The AFAB intended to attract more locators in the manufacturing, Business Process Outsourcing (BPO), electronics industries and green industries. The motivation was to enhance its tourism capabilities by renovating its existing recreational facilities targeting new investors to build hotels, entertainment establishments, duty free shops, resorts, team-building facilities, and sports facilities in order to encourage the influx of local and foreign tourists. The rationale behind government's decision to establish an export-processing zone and Freeport was to facilitate the attainment of the country's development objectives through job creations, training of skilled workers, technology transfer, and increase in foreign exchange earnings. Since the establishment of export processing zone in 1972, the socio-economic and cultural life of the people of Mariveles has never been the same.

\section{The Old Town}

Life then in Mariveles was a typical picture of a rural setting. The classic type of dwelling unit was a single wooden house with aluminum galvanized iron roof. There were also few bahay kubo or nipa ${ }^{16}$ and cogon houses. Out of 2,598 households, $69.63 \%$ had radio. Only $0.25 \%$ had television set and only $1.3 \%$ of the household had refrigerator. ${ }^{17}$ Majority of the houses used kerosene/gas as light. Few houses used electricity for light. The people depended on piped water, artesian well, pump, open-well, spring, and other natural sources for water supply in their houses. Most households used wood as cooking fuel. Others used kerosene electricity, gas, and charcoal. The health and sanitation amenities were very poor and not given much importance. This was very evident among the households, as most of them have no toilet facilities. Only few used flush/water sealed toilets. Some used common or public toilet, open pit, and closed pit.

The 1970 Census of Population showed that the inhabitants of Mariveles were engaged on major industries such as agriculture, hunting, forestry, and fishing (1,434 workers) as means of their livelihood. Some were engaged in manufacturing $(1,074)$; services $(1,017)$; commerce (382); construction (211); transportation, communication, and storage (101); mining and quarrying (74); electricity, gas, water, and sanitary services (19); and industry not adequately 
describe (506). The classes of workers included those who were classified as wage and salary workers both as private $(1,225)$ and as government $(1,008)$ employees. Some were workers in the business either as self-employed $(1,412)$ or as employer $(420)$. Others were classified as unpaid family workers (671). Among the population of 10 years old and over in 1970, the $42.48 \%$ were employed while $3.35 \%$ were unemployed and $55.03 \%$ were economically not active. ${ }^{18}$ Majority of the male populace were engaged in usual occupations such as craftsmen, production process workers and laborers and other related work. On the other hand, the female were preoccupied with housekeeping activities.

For the population of 6 years and over the male literacy outnumbered the female. Both young boys and girls were attending at least elementary schools. However, young boys continued their study up to secondary or tertiary level than young girls. The married females outnumbered the married males even though the male total population during the seventies was higher than female. In fact, the never married male population accounted to $51.40 \%$ compared to the $44.27 \%$ of the female. The priority to acquire higher education or degree was for boys because of the notion that once girls got married, they just stayed in the house to take care of the family. It was enough that girls knew how to read and write. The expectation was that later he would help the family. Besides, he would have his own family to support too in the future.

Tagalog was the dominant language and ethnic group in Mariveles. Other spoken dialects were Pampango, Waray-waray and Bicolano. There was a noticeable increase in the number of Ilocano-speakers in 1973 compared to the 1970 Census. There was no evidence whether the increasing number of Ilocanos to Mariveles has something to do with President Ferdinand Marcos who was an Ilocano himself but the establishment of Bataan Export Processing Zone, which was his pet project, had surely attracted migrants from other provinces. The first years of the BEPZ's operations had slightly affected the major occupational group in 1975 . The 1975 Census of major occupation indicated a slightly increase in craftsmen, production process workers and related laborers (20.3\%). Next were sales workers with $11.4 \%$; service sports and related workers; $8.1 \%$ and workers in transport and communications with $7.1 \%$. Despite the establishment of the Bataan Export Processing Zone, Mariveles remained predominantly a rural area in 1975. Thus, majority of its population were farmers, hunters, loggers, and fishermen by occupations.

The socio-cultural life of the people of Mariveles did not change much in 1975. Aside from the traditional games, swimming or playing in the field was the children's common activities. Both adult men and women unwind through chatting while drinking tuba, gin (ginebra) or shoüktöng ${ }^{19}$. It was typical to see also families attending mass together on a Sunday and having picnic or going to the beach afterwards. The family members together with some neighbours would gather around the radio or television set to listened or watched their favourite program. Early in the morning aside from the rosters' crowed, neighbourhoods normally woke up with the sound of a loud music or the favourite radio program of the resident who might be one of the few who owned radio or television set. Sometimes the songs or the tele-radio ${ }^{20}$ was the topic of discussions among neighbourhood. This characterized the simple rural lifestyle of the people of Mariveless. The BEPZ was only three years old then and just started its full operation. Construction of buildings facilities and other infrastructure were still ongoing. Mariveles remained predominantly a rural area. 


\section{Changing way of life}

Certain socio-cultural changes were happening to the people of Mariveles in the eighties. Its population soared to 48,594 of which $48.96 \%$ were migrants. In fact, since 1980 the municipality became the most populous town of Bataan province. It has high literacy rate with the females generally outstripped the males in literacy rate -56.09 percent against $42.23 \%$. This was contrary to the literacy percentages in the $1970-1975$ Census of Population wherein the males surpassed the females.

Furthermore, there was a shift from the agricultural to production-oriented occupations. The private household populations of 15 years old and over-record $54.12 \%$ of gainful workers while the remaining $45.88 \%$ were in non-gainful activities based on the 1980 Census. In the last two Censal years' respectively, agriculture, animal husbandry and forestry workers, fishermen, and hunters recorded around $42.24 \%$ which consistently form the biggest group of gainful workers. Yet, production and related workers, transport equipment operators and laborers rose by $7.29 \%$ points to $37.06 \%$ in 1980 that leave behind the topmost group of the seventies with only $27.33 \%$. Third in rank were service workers that rose from $0.79 \%$ to $8.52 \%$. This implied that sales workers substantially declined from $11.45 \%$ in 1975 to $8.07 \% \%$. The professional, technical, and related workers had slightly gained at $6.04 \%$ to $0.72 \%$. The clerical workers had likewise grown from $4.19 \%$ to $5.20 \%$ while administrative, executive and managerial workers fell from $1.35 \%$ to $0.86 \%$. Decrease in the proportions of the aforementioned gainful occupations was attributed to a mark increased in the proportion of workers not classifiable by occupation, which suddenly hiked from $1.49 \%$ to $6.92 \%$. Due to the higher proportion of housekeepers, the rural areas had lower proportion of gainful workers (51.50\%) compared to the urban areas gainful workers $(57.13 \%)$. As expected rural areas had more than twice as many agricultural, animal husbandry, and forestry workers, fishermen, and hunters than the urban areas while the urban areas produce more production and related workers. As more pasture and agricultural lands were converted into industrial and residential lands to accommodate the continuous expansion of the export-processing zone, the number of non-gainful occupations also lessened.

The 1980 Household Census of Population showed that most of the households in Mariveles were residing in their own dwelling units. Others were tenant/lessee or renting free. There were few dwellers of own improvised barong-barong and lodging house, dormitory, etc. The occupants of the apartment, duplex, or dormitory were usually workers from the zone provided by their respective employers certain housing benefits. Roofs of strong materials such as galvanize iron/aluminum; tile/concrete, brick or stone and asbestos were the typical dwelling units. Households in dwelling units with roof of strong materials were common sight in both urban and rural areas of Mariveles. A greater proportion of the total numbers of households depend largely on the faucet, community water system than on any other source of water supply whether for drinking, for kitchen use and for washing clothes. Like the other municipalities of Bataan, Mariveles felt the massive electrification program of the government. Electricity had replaced kerosene as the most common type of lighting used. The use of liquefied petroleum gas replaced kerosene both in the urban and rural households. Only small proportions in the rural areas still used oil and other kinds. The type of cooking fuel varied from wood, charcoal, kerosene, and LPG. There were only variations in the proportions of urban and rural households in the use of a particular cooking fuel. Moreover, the increasing number of households owning radios, television sets, and refrigerators were attributable to the greater economic opportunities available to the residents of Mariveles with the establishment of Bataan Export Processing Zone. 
There was also an improvement in the type of toilet facilities in the town of Mariveles during the eighties. The urban households had better toilet facilities than their rural counterparts. Majority of the urban households used the water-sealed with sewer/septic tank while a small proportion used water-sealed with other depository, closed pit, open pit and other types. The rural households used the same type of toilet facilities except for $40.0 \%$ without proper toilet facilities. ${ }^{21}$ Those were the barangays located in the outlying areas, closer to bodies of water. The used of rivers, streams, and other bodies of water in the fifties and sixties was the same in the rural areas of the eighties (based from oral history and informal interviews with the old folks). The common scenario was that near the main source or the upstream, the water was for drinking and cooking. Meanwhile downstream was for washing clothes, bathing, and other personal needs including toiletry. This was the reason why until the eighties the common sickness were diarrhea, skin infections, scabies, pediculosis, (head lice infection), worm infection, colds, fever, flu and other related sickness due to poor hygiene and sanitation. ${ }^{22}$ However, there was no doubt that because of the Bataan Export Processing Zone, the lifestyle of the people of Mariveles had improved a lot in the eighties compared to the seventies.

In the same manner, female migration in the household population of 5 years and over of those who lived in the same municipality $(86.48 \%)$, in another municipality but within the same province $(98.03 \%)$, in another province $(90.83 \%)$ and even those of foreign country $(60.46 \%)$ had exceeded the male migration. ${ }^{23}$ Again, a portrayal of how employment affected the sex ratio of the total household populations. Manufacturing was the biggest industry group in the exportprocessing zone that concentrated on textile, garments, wearing apparel and leather, etc.

The plurality of the dialects spoken by the people in the nineties indicated the diversity of the population. Aside from the local languages, Chinese and English languages were dominant among the foreigners. Those foreigners worked in the economic zone. Majority of the household population of 15 years old and over were in the labour force. Only $4.7 \%$ were unemployed and about $35.50 \%$ were not in the labour force ${ }^{24}$. Those who were not in the labour force were students, housekeepers, senior citizens and those whom because of disabilities could not work.

The single house (74.98 percent) was the typical dwelling unit in the nineties. Some people occupied a multi-unit residential, duplex, institutional living quarters, etc. Most of these housing units had roofs made of galvanized iron/aluminum and used concrete brick or stone. However, there were significant numbers of housing unit in rural areas that used cogon or nipa as roofs and the outer walls made of bamboo or sawali. Owners of this type of housing were migrants from other provinces who tried their luck in Mariveles. Without a house or own land to stay, they tend to squat in vacant lands somewhere in the rural areas. Slowly, as this type of migrants increased, they built a small village of their own. The local people called them as the village of Ilocanos or the Bisayas depending upon their province of origin. When they have a stable income, they rent or transfer to a better housing conditions.

When the influx of migrants who settled in one particular place continued then they form new community or barangays. Land owned or land amortized was the common tenure of lot in the urban areas (75.44\%) than in the rural areas (24.55\%). The old folks of Mariveles normally occupied their own lots. The government awarded those lots to them or the "rights to occupancy" long time ago. Those who owned hectares of lands usually got ownership through inheritance. Those were the lands sold and developed into exclusive subdivisions or villages and other real estate development by the government or private foreign or local individuals or corporations. The town of Mariveles continued to progress as the years passed-by. Hand on hand with the success of the Bataan Economic Zone was the local community's progress. The single houses 
with galvanized iron/aluminum with walls made of concrete, brick, or stone and half-concrete, brick, stone and half-wood was the common type of dwelling unit. Roofs made of cogon, nipa or anahaw was already lessen. The unavailability of these kinds of materials plus the lack of strength against strong typhoon decreased the preference for this type of roofing. Houses built on bamboo, cogon, nipa and anahaw were viewed as house of the poor while concrete, bricks and stone with galvanized iron or aluminum roofs were for the rich. In addition, majority of the households lived in lots that they owned or amortized. Single-housing unit in a subdivision became a fashion among the people of Mariveles. That type of dwelling units continued to flourish. Living to subdivisions was a trend for the economically affluent local residents. The subdivision was an indicator of social and economic status. The type of houses, size of lots and amenities indicated whether it was a high-end, middle, and privately owned or governmentfinanced subdivision. There were higher percentages of people who rented (83.99\%), occupied lots free with consent of the owner $(60.87 \%)$, or occupied lots free without consent of the owner $(91.25 \%)$ in the urban areas than in the rural areas. ${ }^{25}$

Ownership of family vehicle whether it was a car, jeep-type-owner, and tricycle was part of the changing lifestyle of the people. In the past, public transportation such as jeepneys ${ }^{26}$ and mini-buses were the only vehicles available. People used to walk afar. Few rode on their horses and carabaos ${ }^{27}$. Inter-island transportation used bancas ${ }^{28}$ or boats. With the improvement of the roads, big busses and private vehicles became a common means of transportations aside from the jeepneys and mini-buses. Private cars or "school service" brought children to school. In addition, the availability of private schools for elementary and high school education gave an option for the well-to-do families to send their children in a private school. In the past, public schools in all levels were the only alternative for the families aside from education outside the town, which was expensive that time. Affluent families sent their children to Manila or at least to the capital city for tertiary education. The only tertiary school in Mariveles that time was the Polytechnic University of the Philippines while the Local Manpower Office provided short or vocational courses.

There were recreational facilities such as bowling lane, tennis, and basketball courts. There were also theaters or cinemas for moviegoers. These were the new recreational activities available for the people of Mariveles, especially the workers of the Bataan Economic Zone. The local inhabitants enjoyed also the benefit of buying export quality products intended only for export market through the annual BEZ Trade Fair. Townspeople and tourists from other places looked forward for this fair. Outsiders sometimes called Mariveles as the "Town of Adidas and Nike shoes," or "Town of Barbie and Ken," the dolls produced by Mattel Philippines, Incorporated. In the recent years, Mariveles became popular also because of beautiful beaches surrounding the whole town. Local and foreign tourists were continuously visiting the town to enjoy the white beaches or the dark black sands. Frequently visited were the reserved ecosystem and natural parks. The continuous flow of foreign and local visitors, the influx of migrants, and the availability of livelihood - all these were contributors to the economic growth of Mariveles.

Aside from the increased in population that made Mariveles as the most populous Municipality of Bataan, the most significant contribution of industrialization to Mariveles, was the economic gains the town had achieved in terms of revenue collections. In Year 2001, Mariveles topped the revenue collection performance amounting to P121, 581,325.45 among the eleven towns and one city in Bataan making it the richest Municipality in the province. ${ }^{29}$ It was also the year that Mariveles became a first class municipality. The presence of both multinational 
and local firms and other businesses made the Municipality to be the undisputed number one in terms of revenue collection in Bataan and the richest town in the province.

Literacy rate recorded at $98 \%$ wherein the number of the females attained higher level of education especially in the year $2000 .{ }^{30}$ Of the total population, aged 5 years and over, $31.6 \%$ attended or completed elementary education while $37.4 \%$ reached or finished high school and $7.2 \%$ were college undergraduates. There were about $8.2 \%$ of the household populations with academic degree holders. Among those with academic degree, the females (58\%) outnumbered the males $(42 \%)$. Similarly, there were more females $(59.9 \%)$ than males $(40.1 \%)$ among those with post baccalaureate courses. These influenced the percentage of the major gainful occupations in the 2007 to 2010 Census of Population. In the percentages of occupation wherein the two sexes were involved, the females were into professional and administrative jobs than their male counterparts. Meanwhile they were more males who work as plant and machine operators and assemblers, laborers and unskilled workers.

Figure 3: Educational Facilities Within the Economic Zone and Freeport Area ${ }^{31}$
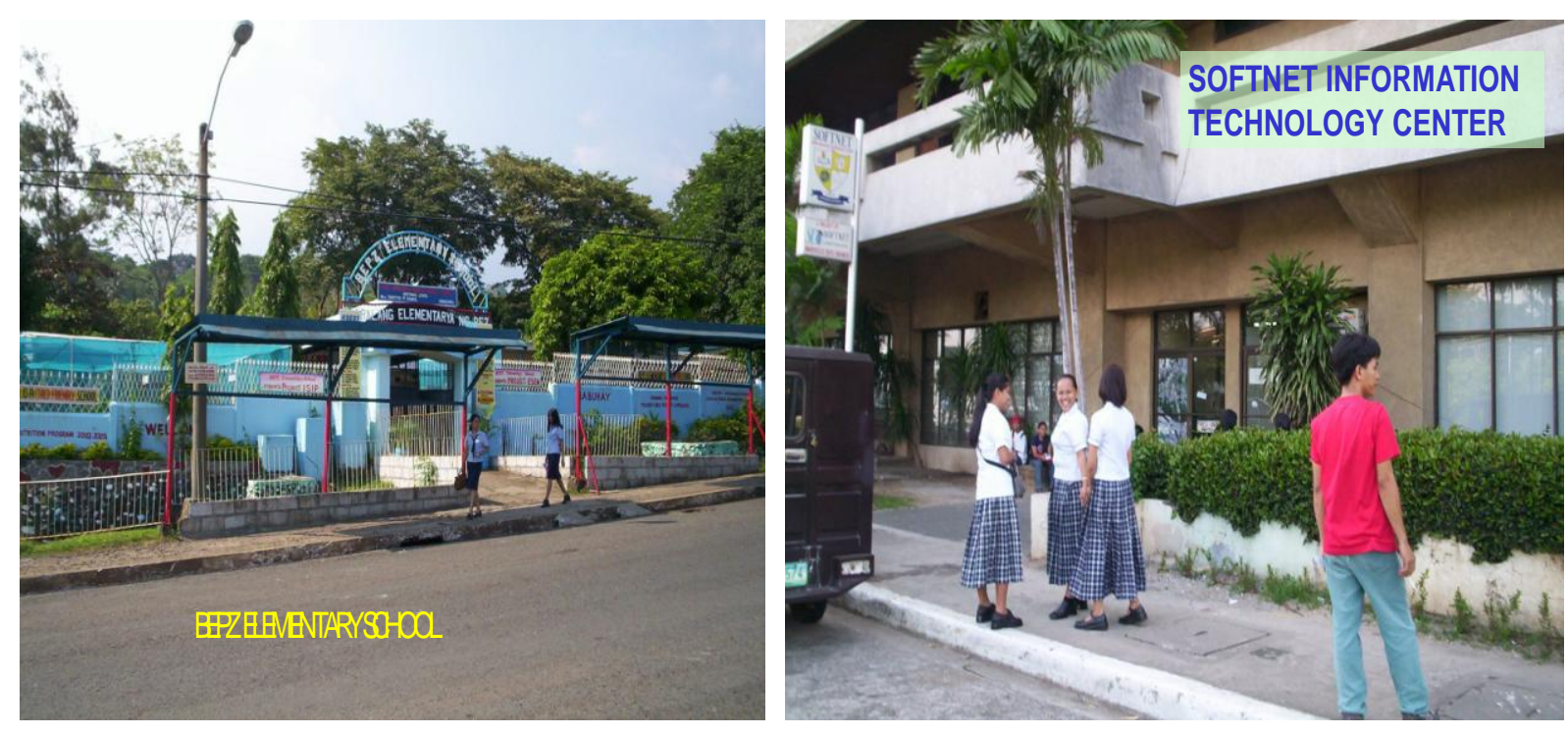

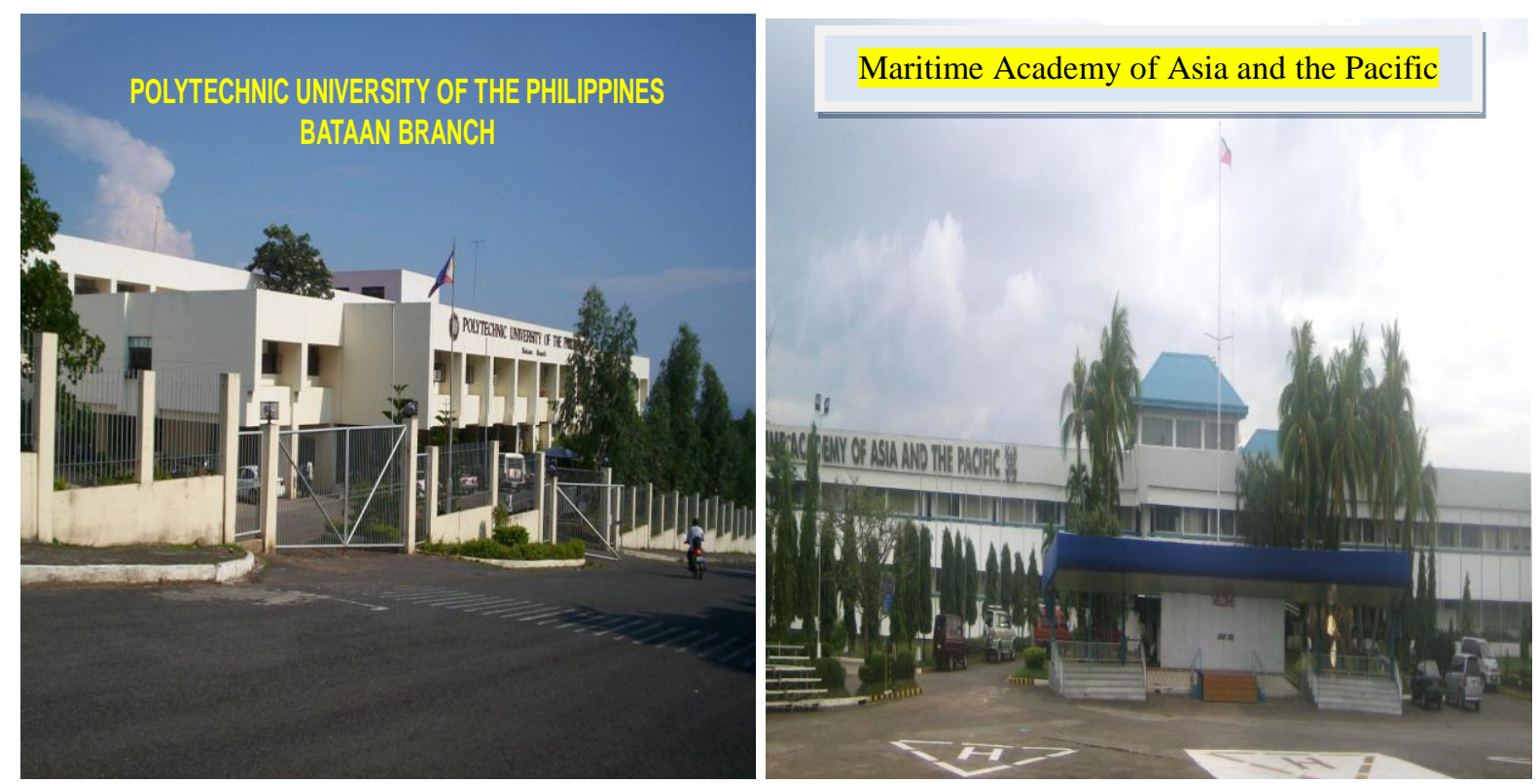

In both classifications of Professionals and Technicians and associate professionals, the female slightly dominated the male by $31.51 \%$ and $34.26 \%$ respectively. Likewise, in the classification of Officials of government and special interest organizations, corporate executives, managers, managing proprietors, and supervisors, the female outnumbered the male workers by $14.49 \%$. However, in the classifications of Service workers and shop and market sales workers (52.84\%); farmers, forestry workers and fishermen (49.07\%); Trade and related workers (19.12\%); Plant and machine operators and assemblers (82.7\%); and Laborers and unskilled workers $(28 \%)$--- the male outnumbered the female workers by the above percentages. The presence of medium to heavy industries as defined by the road construction, port and shipping industries, coal-fired power plant and real estate development explained the dominance of male workers in these major occupational classifications. Moreover, the Bataan Economic Zone and Freeport Area of Bataan Report on 2013 indicated that inside the zone about half of its locators or firms were engaged in Garment and Textile Industry, $16 \%$ were producing bags and rubber products, $2 \%$ manufacture electronic parts, while the remaining $36 \%$ process other varieties of finished goods. ${ }^{32}$ These categories of jobs preferred female workers than male workers. Even with the presence of medium and heavy industries inside the Zone, the majority of the firms and locators were garment and textile industries that preferred female workers. Thus, the over-all population of the Export Processing Zone and of Mariveles remained a female dominated population. 
Figure 4: Bataan Economic Zone ${ }^{33}$

Old Administration Building

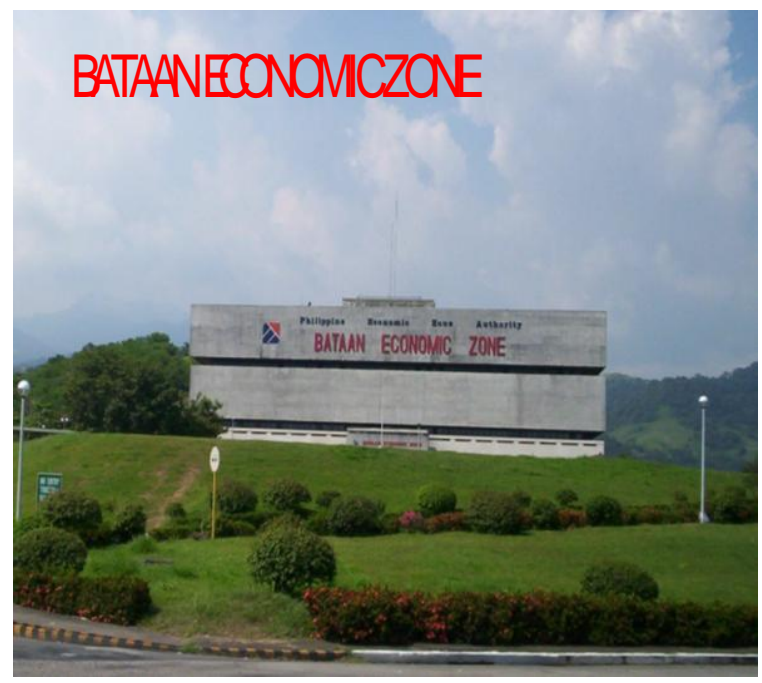

Figure 5: Freeport Area of Bataan ${ }^{34}$

New Administration Building

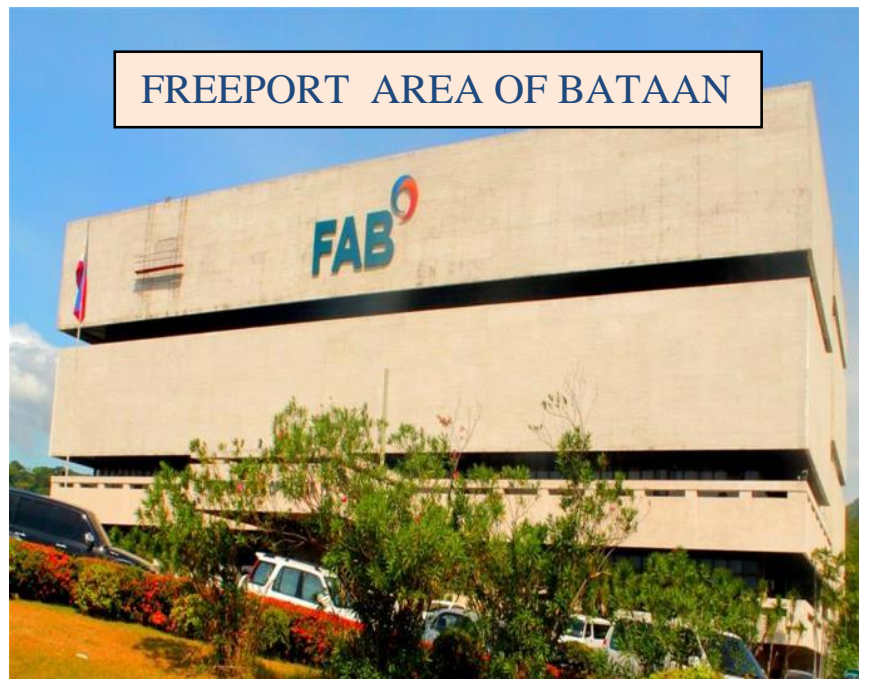

Aside from the bigger chance for women to work inside the Zone and on other companies nearby, the domestic responsibilities remained on the women's shoulder. However, some family changes were observable. The absentee parent was common among the economic affluent family. The presence of house servants as substitute to the working mothers was typical. The modern gadgets or recreation outside the home replaced the traditional family recreation or bonding. Similar with the challenges faced by the families in the urban community, the people of Mariveles has to cope with the changes brought about by industrialization.

Based on the 2010 census, the male overseas workers outnumbered the female overseas workers. This was in contrary to the ratio of workers in the Zone as the female workers outnumbered the male workers. They were, however, more males working overseas than females. Though working abroad had attracted many Filipinos, there were significant numbers among the people of Bataan and Mariveles who preferred to work in the Zone. The proximity to the family was the common reason for staying in their hometown. Otherwise, the males worked overseas while the female family members remained to look after the household. These were the reasons for the outnumbered population of female over male working in the export-processing zone.

The development of the export-processing zone or economic zone provided work for the local residents and attracted thousands of migrants to settle in the town. The growth of the industry generated also self-employment in the surrounding localities. The salaries and wages flowed into the local economy created small-scale to big enterprises such as sari-sari store, eatery, laundry shops, computer shops, beauty parlor, mall, restaurants, and other real estate development. As people tend to spent much, prices of basic commodities soared up. Eventually this provided gainful livelihood for small and medium entrepreneurs in the locality. The reason was not the lack of supplies as commercial establishments were like mushrooms sprouting everywhere in the area. The town became so populous and people were willing to spend parallel to their new lifestyle. All these depicted the socio-cultural and economic changes in the life of the inhabitants of Mariveles. 


\section{Conclusion}

The socio-cultural life of the people of Mariveles had changed much in years. Agriculture was the chief source of livelihood along with fishing, forestry, etc. People lived a simple community life. The immediate and long-term effect of the establishment of Bataan Export Processing Zone was population increased. Since 1980, Mariveles became the most populous municipality of the province. The ones picture of a rural town with low population rate and small settlement has gone. The unstoppable arrival of migrants who then settled permanently in Mariveles was very significant. Those migrants did not only add to the counting of population, they brought with them certain ways of living that were integrated in the cultural life of the local inhabitants. To quote Henry Scott, "Today's natives are yesterdays' visitors." Along with the arrival of these visitors, the local folks assimilated new languages or dialects, food, transportation, houses, vehicles, clothes and other non-material culture. After decades, they were no longer visitors rather they counted as part of the ethnic groups comprising the population of Mariveles. It became a town of diverse Filipino and foreign cultures. Local migrants flocked to the municipality for job and livelihood opportunities. Foreign expatriates associated with export manufacturing firms also established their residence in the area. The nature of work available in the Zone has influenced the sex ratio of the population. Manufacturing of garments, textiles, apparels, electronics were the dominant industries. Those kinds of jobs preferred female workers than male workers. Thus, even the percentages of migrants were female dominated.

Mariveles has a very high literacy rate. However, there was a shift in the priority of children's education. The priorities to finish higher education in the past years were for males not for females. This was no longer the family practice in the recent years. Females have equal importance if not more importance in education. The Export Processing Zone opened a venue for women not to remain simply as housekeepers or be involved in non-gainful activities rather they engaged in productive and gainful activities. As the women acquired a degree, they worked in administrative and professional jobs and not simple labourers. On the other hand, men worked as labourers, unskilled workers, plant and machine operators, and assemblers. For those who acquired degree, they worked also as administrators and managers.

The availability of livelihood has continuously improved the living condition of the people. Acquisition of properties such as house, car, and other material things defined the social and economic status of the family. Even accessed to private and higher education was a determinant. Education became a privilege of the economic affluent. It was common to see both parents working to support the family needs. The hired servant took care of the housekeeping. This was a deviation to the traditional Filipino family practices. The mother preoccupied herself in child-rearing and household chores while the father provided the financial needs of the family. The changing lifestyle and Filipino values had affected much the family practices. Even the old practice of attending Sunday Mass and family recreation together were vanishing because of an absentee parent and the attraction of recreational activities outside the home.

The manifested impact of the Bataan Economic Zone to the socio-cultural life of

Mariveles perhaps was immeasurable. Nevertheless, the economic influenced which led to these changes were obvious. The transition from rural to urban life characterized these changes. However, there were still some barangays considered as rural, the proximity of these barangays naturally led to the sharing of culture. The migrants did not only transmit their way of life to the local community. The latter also shared their culture to the migrants. This resulted to diffusion of culture among the peoples of Mariveles. 
As the economic zone and Freeport area progressed, its effects overflowed to the local community. Thus, Mariveles was the witnessed and the collaborator in the different phases of the Zone's development. Whatever changes happened to the Zone affected the local residents. The inhabitants of Mariveles were part of the Zone. The residents were stakeholders who benefitted and participated in the zone's development.

\section{Notes}

${ }^{1}$ Mariveles is a first class municipality in the province of Bataan Philippines. It is composed of eighteen barangays out of which, five barangays are hosting the locators of Freeport Area of Bataan and Economic Zone.http://www. Mariveles. gov.ph. Accessed September 12, 2015.

${ }^{2}$ Bataan is a province of the Philippines. The province is part of the Central Luzon region. The capital of Bataan is Balanga City and it is bordered by the provinces of Zambales and Pampanga to the north. The peninsula faces the South China Sea to the west and Subic Bay to the north-west, and encloses Manila Bay to the east.http://www Bataan.gov.ph. Accessed September 12, 2015.

${ }^{3}$ Corregimiento is a Spanish term used for country subdivisions for administrative purposes. Babylon Dictionary, 2015.

${ }^{4}$ Municipal Planning \& Development Office Record, History of Mariveles, Municipality of Mariveles Office of the Mayor, 2010.

${ }^{5}$ Katipuneros are members of the Katipunan, a secret Philippine revolutionary society founded by anti-Spanish Filipinos in Manila in 1892 whose primary aim was to gain independence from Spain through revolution. Teodoro C. Agoncillo, "History of the Filipino People" (8th ed.). Quezon City: Garotech Publishing, 1990.

${ }^{6}$ Death March is the forcible transfer from Saisaih Pt. and Mariveles to Camp O' Donell by the Imperial Japanese of 60,000-80,000 Filipino and American prisoners of war which began on April 9, 1942, after the three-month Battle of Bataan in the Philippines during World War II. The march went from Mariveles Bataan, to San Fernando Pampanga. From San Fernando, survivors were loaded to a box train and were brought to Camp O'Donnell in Capaz Tarlac. See discussion in Stanley L. Falk , "Bataan: The March of Death", New York: W. W. Norton \& Company, 1962; Tom Lansford, "Bataan Death March", In Stanley Sandler. "World War II in the Pacific: an encyclopedia". Taylor \& Francis, 2001, pp. 159-160.

${ }^{7}$ Municipal Planning \& Development Office Report. Municipality of Mariveles Office of the Mayor, 2014.

${ }^{8}$ Ibid.

${ }^{9}$ Bataan Export Processing Zone (BEPZ) is the pioneering export-processing zone located in the town of Mariveles in the province of Bataan, Philippines. Export Processing Zone Annual Report, 1975.

${ }^{10}$ EPZA News. Information and Promotions Department. EPZA Mariveles Bataan. March 1975 issue.

${ }^{11}$ IBON Foundation, Inc. "Export Processing Zone: Path Towards Industrialization?” Manila, 2005.

${ }^{12}$ Presidential Decree No. 66, Section 1. Declaration of Policy. "It is hereby declared to be the policy of the government to encourage and promote foreign commerce as a means of making the Philippines a center of international trade, of strengthening our export trade and foreign exchange position, of hastening industrialization, of reducing domestic unemployment, and of accelerating the development of the country, by establishing export processing zones in strategic locations in the Philippines". Approved on Nov. 20, 1972. http://www.chanrobles virtual law library. Accessed July 6, 2015.

${ }^{13}$ Ibid.

${ }^{14}$ Marvin Castell. Assessing the Role of Government Institutions Supporting Industrial Adjustment in the Philippines: The Case of PEZA, CITEM and DBP. www.dlsu.edu.ph/research/centers/aki/_pdf Accessed September 9, 2015.

${ }^{15}$ Ibid.

${ }^{16}$ Bahay Kubo or Nipa Hut is a type of stilt house indigenous to most of the lowland cultures of the Philippines. It often serves as an icon of broader Filipino culture, or, more specifically, Filipino rural culture. The traditional bahay 
kubo follows the centuries-old Southeast Asian rural archetype of the single-room dwelling where all family activities happen in one space. After sleeping mats are rolled up in the mornings, the same space is given over to daytime activities that sometimes spill outdoors to the shaded areas underneath the house". See discussions in Jonathan H. X Lee, "Encyclopedia of Asian American folklore and folklife", Vol. 1. Santa Barbara, Calif.: ABCCLIO, 2011 p. 369; Rachelle Cruz, 2013-08-“The Bayanihan: Art Installation at Daniel Spectrum: The Philippine Reporter", Toronto, Ontario Canada. The Philippine Reporter (Toronto, Ontario, Canada). Retrieved 201-8-15; Augusto F. Villalon, "Bahay Kubo and the Filipino Concept of Space: Under one roof", Philippine Daily Inquirer Internet Edition, June21,1999. Accessed July 8, 2015.

${ }^{17}$ Philippine Statistics Authority-National Census and Statistics Office, Census of Population, 1975.

${ }^{18}$ Ibid.

${ }^{19}$ Shoüktöng is a traditional wine or drink in the rural Philippines (source).

${ }^{20}$ Tele-radio is a drama anthology in the radio.

${ }^{21}$ Philippine Statistics Authority-National Census and Statistics Office, Census of Population, 1980.

${ }^{22}$ Ibid.

${ }^{23}$ Ibid

${ }^{24}$ Ibid, $1990-1995$.

${ }^{25}$ Ibid, $2000-2010$.

${ }^{26}$ Jeepneys are the most popular means of public transportation in the Philippines . They are known for their crowded seating and kitsch decorations, which have become a ubiquitous symbol of Philippine culture and art. Jeepneys were originally made from U.S. left over from World War II. Then American troops began to leave the Philippines at the end of World War II, hundreds of surplus. Jeeps were sold or given to the Filipinos. The Jeeps were stripped down and altered locally: metal roofs were added for shade; and the vehicles decorated in vibrant colours with chrome- plated ornaments on the sides and bonnet. The back saloon was reconfigured with two long parallel benches with passengers facing each other to accommodate more passengers. The size, length and passenger capacity has increased as it evolved through the years. Karen Lema, "Manila's jeepneys pioneer fears the end of the road", Reuters, 2007. Keijiro Otsuka,; Masao Kikuchi; Yujiro Hayami. "Community and Market in Contract Choice: The Jeepney in the Philippines". Economic Development and Cultural Change, January 1986, Vol 34, 2 pp. 279-298.

${ }^{27}$ Carabao is a swamp type domestic water buffalo found in the Philippines. It is considered as the national animal of the Philippines. FAO, Philippine Carabao/Philippines In: "Domestic Animal Diversity Information System", Food and Agriculture Organization of the United Nations, Rome, 2013; Dante M Aquino; Gerald A. Persoon, "Tradition and Change: Beer Consumption in Northeast Luzon, Philippines" In Wulf Schiefenhovel; Macbeth, Helen," Liquid Bread: Beer and Brewing in Cross-Cultural Perspective", of Anthropology of Food \& Nutrition, Berghahn Books, 2013, Volume 7 p. 197. Accessed July 30, 2015.

${ }_{28}$ Banca is a small boat found in Pacific waters especially around the Philippines. Usually a dugout canoe often provided with outriggers and a roof of bamboo". Merriam Webster Dictionary 2015.

${ }^{29}$ This is an Official Website of the Local Government of the Municipality of Mariveles. http://www.Mariveles.gov.ph. Accessed June 6, 2015.

${ }^{30}$ Philippine Statistics Authority- National Census and Statistics Office, 2000.

${ }^{31}$ Bataan Economic Zone Report of 2008 is based on the Official Records released by the Philippine Economic Zone Authority (PEZA). The Bataan Economic Zone Report is an annual report submitted to the Philippine President and to the Board Members.

${ }^{32}$ This is an Official Website of the Authority of the Freeport Area of Bataan, the governing authority of the Freeport Area of Bataan located in the Municipality of Mariveles in the province of Bataan, Philippines http://www.freeportareaofbataan.gov.ph. Accessed June 27, 2015.

${ }^{33}$ Ibid.

${ }^{34}$ This is based on the Official Records released by the Authority of the Freeport Area of Bataan (AFAB). The Authority of the Freeport Area Report of 2014 is an annual report by AFAB submitted to the Philippine President and to the Board Members. 